\title{
Knowledge, Attitude and Practice of Hand Washing among Mothers of Children 0-59 Months of Age in Lagos Nigeria
}

\author{
Abigail Odozi Ogwezzy-Ndisika*, Tommy Solomon \\ Department Of Mass Communication, University of Lagos, Lagos, Nigeria
}

Copyright $(2019$ by authors, all rights reserved. Authors agree that this article remains permanently open access under the terms of the Creative Commons Attribution License 4.0 International License

\begin{abstract}
This study examined the knowledge, attitudes and practice of hand washing among mothers of children 0-59 months of age in Lagos Nigeria. The descriptive survey method was used to gather data for the study. The study was conducted in three local government areas of Lagos. The local government areas are Eti-Osa, Lagos Mainland and Alimosho. 934,886 female residents of the three local government areas formed the population of study while 406 respondents formed the sample size. Purposive sampling technique was used to select the respondents. The study found that 7 in 10 mothers of children 0-59 months of age had high exposure to the campaign about the danger of dirty hands (73.8\%). About 6 in 10 of them similarly had high knowledge of the subject matter and as a result, mothers who were knowledgeable about hand washing practiced it. It concluded that has been a gap between recommendations on improving hand washing practice and actual actions on such recommendations. Hence, this study recommends that intervention efforts should address the infrastructure gaps that negatively impact on the availability of these hand washing-boosting factors, particularly, access to water, if improvement is to be achieved in terms of practice.
\end{abstract}

Keywords Hand Washing, Knowledge, Attitude, Practice, Child Survival, U5MR

\section{Introduction}

There is high mortality rate among children less than five years in Nigeria. According to the National Population Commission and ICF International, the Nigeria Demographic and Health Survey, mortality rate was 157 per 1000 live births and child mortality rate was 75 per 1000 live births in 2008. In 2013, the figure was 128 and 69 deaths per 1,000 live births, respectively [16]. India's 24 percent and Nigeria's $11 \%$ together constitute more than $30 \%$ of children less than five years mortality rate globally. Child mortality figures released by UNICEF in September 2013 show that some 2,000 children under five years of age die each day from diarrheal diseases, with a vast majority of them contracting these diseases as a consequence of lack of safe water, sanitation and basic hygiene. [15] The global figures suggest that at an average of 121 children of under five years' deaths, Sub-Saharan Africa is the worst-hit region, followed by South-East Asia, the Eastern Mediterranean Region, and the Western Pacific Region, and lastly the European region [10].

Globally, infectious diseases remain leading causes of childhood morbidity and mortality. They are also account for $64 \%$ of all deaths in children under five years of age ${ }^{[9]}$. Diarrhea is responsible for $19 \%$ of all childhood mortality while pneumonia is the cause of $16 \%$ those deaths. Similarly, respiratory tract infections joins as the most familiar causal factors for morbidity and mortality among under five years children, especially those in low and middle-income countries, and it is the children in the lowest socio-economic cadre who suffer the highest morbidity and mortality rates [11] [12] [13]. It is human contact with bacterial pathogens through contaminated hands or generally sub-optimal hygiene that that directly causes these diseases [8] [14]

One of the most effective and least disruptive hygiene-promoting practices is hand washing. Hand washing, especially with soap, is considered to be one of the most cost-effective practice which can enhance personal and ultimately, public health [19]. Different studies have shown that hand washing is key in hygiene management in a bid to reduce under five years mortality [13] [20]. Simple action of washing hands with soap (with particular reference to washing hands at the critical times) can break off the transmission of the pathogens that cause diarrhea and pneumonia. Reviews of epidemiological studies suggest that common practice of hand washing with 
soap could decrease the threat of severe diarrhea by $48 \%$ and the possibility of any diarrhea by $47 \%$. Further reviews conclude that hand washing with soap could reduce the risk of conditions like pneumonia by up to $23 \%$. [22] [23] [24] Most recently, the Ebola pandemic has hit some countries in Africa, Nigeria inclusive, killing over 8,000 people [25] [26]. In the awareness campaigns to ensure proper health behavior in controlling the spread of the virus, hand washing, when done right, has been identified as one of the key means of achieving this objective [27] [28].

Assuming that the number of lives saved is comparative to the reduction in disease risk, one can infer that that the lives of 0.603 million children aged 1-59 months may possibly be saved annually from diarrhea and pneumonia by hand washing with soap [2] [29] [30].

However, beyond just washing hands, the emphasis in most literature is on the critical times that hand washing must be undertaken. Hand washing is considered as properly done when it is:

- Done for a minimum of 30 seconds

- Done with a combination of soap or ash and, preferably, running water

- Done at critical times including (a) before eating, (b) after handling child's faeces, e.g. changing diapers, (c) before preparing food, (d) before feeding a child, (e) after defecating.

In Nigeria, according to a study conducted in 2013 by Isibor, the average rate of hand washing after using the toilet stands at a $3 \%$ in rural Nigeria, which is a far way beyond the global average of $17 \%$ [31]. In Ghana, the National BCC Strategy for 2011 cites results of studies done on reported patterns of hand washing, especially during critical times, and reports that after average rates after using the toilet $(90 \%)$, before meals $(86 \%)$, after meals $(62 \%)$, after changing dippers $(29 \%)$ and after visiting the urinal (23\%). In Malawi, hand washing practice after using toilet is around 35 percent. A study in Bangladesh found that at critical times, hand washing rates stood at $34 \%$ after defecation, while only $1 \%$ of rural dwellers were observed to wash their hands before feeding a child, which was not the case in Ghana ${ }^{[32]}$. It went on to note that in most cases, hand washing was only engaged in when the hands were perceived to be dirty, as evidenced most times by the presence of dirt under the fingernails.

Literature on effective hand washing highlights the importance of stemming the faecal-oral contact as this was the major means by which diarrhea can be contracted. Contact between contaminated hands and food (and the face) is also mentioned, especially with reference to both diarrheal and respiratory infections as well as eye infections. It is therefore expected when studies show that hand washing at the above-mentioned critical times, especially when faeces are contacted, reduces diarrheal prevalence in under five years children by up to $47 \%{ }^{[2]}$ and respiratory infections by up to $30 \%{ }^{[26]}$. There are several studies which show the extent to which compliance to hand washing at crucial times.

Hence, study of knowledge, attitude and practices (KAP) of hygiene (hand washing) remains essential in African countries, especially with the different intervention programmes being championed by government, multinational companies - via a shared values approach to corporate social responsibility (CSR), community-based groups and philanthropic individuals. These interventions are designed to respond to the gaps in KAP, especially given the degree to which regular hand washing is accepted as a norm. This research study is therefore on knowledge, attitude and practice of hand washing among mothers of children less than five years in Lagos State.

\section{Methodology and Data Collection}

The aim of this study was to determine the extent to which mothers of children less than five years in Lagos State know of handwashing as a practice and the extent to which this knowledge influenced hand washing practice among them. The study focused on the opinion of mothers of children who were less than five years on their hand washing knowledge and practice.

\section{Research Design}

The research approach was non-experimental, quantitative and descriptive.

\section{Method}

Survey method was employed to gather data in three purposively selected local government areas in Lagos State. The three local government areas are Alimosho, Eti Osa and Lagos Mainland. They were selected based on socio-economic category (SEC) to include high income (Eti-Osa), middle income (Lagos Mainland) and low income (Alimosho). Inclusion criterion covered nursing mothers with children less than five years.

\section{Population}

The study population comprised all the women in these three local government areas. The census conducted in 2006 by the Nigerian government puts the population at 934,886 . The breakdown is as follows:

Eti-Osa $=156,132$

Lagos Mainland $=124,933$

Alimosho $=653,821$

Total $=934,886$

\section{Sample Size}

The sample studied was 406, determined based on proportion relative to the total population of women in each 
of the local government areas. The distribution per local government area amounted to 51 (Eti Osa), 80 (Lagos Mainland) and 275 (Alimosho).

\section{Inclusion/Exclusion Criteria}

Only mothers with children of less than five years were selected while women who were unmarried, either as a result of loss of husbands, divorce or separation, or not nursing any child under the age of five years, were left out.

\section{Sampling Technique and Procedure}

A purposive sampling technique was adopted to select the respondents. Purposive sampling is one of the non-probabilistic sampling techniques, which allows researchers to set inclusion/exclusion criteria for respondents-to-be. For this study, the sampling technique ensured that only relevant women with children less than five years were selected as respondents.

The respondents selected on face to face basis. In Lagos state, like other states in Nigeria, local government areas are subdivided into wards. For instance, Alimosho is divided into seven wards, Eti Osa has eight wards and Lagos Mainland has nine wards. Each of these wards has an average of 15 streets. To make it manageable, four wards were selected in each of the local government areas with survey carried out within their streets. Not all houses in the selected wards had mothers with children who were less than five years, purposive sampling ensured that there were more streets to choose from to select the respondents in their houses.

\section{Research Instrument}

The instrument used for this study was questionnaire. The questionnaire contained 18 relevant variables, including demographics. The questionnaire was designed with close-ended variables.

\section{Response Rate and Data Analysis}

A response rate of $92 \%$ was achieved as out of the 406 questionnaire copies administered. This indicates 374 were properly filled and suitable for analysis. Collected data were subjected to statistical analysis using SPSS 20 which looked to test awareness and knowledge level as well as practice of hand washing among mothers of children that were less than five years in age.

\section{Results}

Variables on awareness, knowledge and practice were recorded during analysis into high, low or no awareness, knowledge and practice. The following are the results.
Table 1. Hand washing awareness level

\begin{tabular}{|c|c|}
\hline Number of respondents & \\
Awareness, $\mathrm{n} \%$ & $(\mathrm{n}=374)$ \\
High awareness & $276(73.8 \%)$ \\
Low awareness & $90(24 \%)$ \\
No awareness & $8(2.1 \%)$ \\
\hline
\end{tabular}

Table 1 shows that majority of mothers with children less than five years had become aware of the information about hand washing. This has created high awareness such information.

Having established that majority of the mothers of children less than five years were well aware of information on hand washing, their knowledge of it was tested with statements that emanated from hand washing information. The statements were recoded into high, low and no knowledge. Would high awareness result in high knowledge? The result is presented in table 2 below.

Table 2. Hand washing knowledge level

\begin{tabular}{|c|c|}
\hline Number of respondents & \\
Knowledge, $\mathrm{n} \%$ & $(\mathrm{n}=374)$ \\
High knowledge & $253(67.7 \%)$ \\
Low knowledge & $121(32.3 \%)$ \\
No knowledge & $0(0 \%)$ \\
\hline
\end{tabular}

Table 2 shows the level of knowledge possessed by mothers of children less than five years about hand washing. What the table indicates is that about 6 in 10 mothers sampled had high knowledge of what hand washing means (67.7\%). Another group of less than $40 \%$ had knowledge but such knowledge was low. What this shows is that there is a mix display of knowledge by the respondents. But the table means those who had adequate knowledge of what hand washing is all about, and its implications, are in the majority. The indication that has emerged here is that high awareness has led to high knowledge.

Furthermore, the study tried to establish the attitude of mothers with children less than five years to information about hand washing. Some statements were used to test the attitude of sampled mothers. These statements were then recoded into positive, negative and neutral attitude. The table below established the attitude held by mothers over hand washing.

Table 3. Attitude of mothers

\begin{tabular}{|c|c|}
\hline Number of respondents & \\
Attitude, $\mathrm{n} \%$ & $(\mathrm{n}=374)$ \\
Positive attitude & $348(93.2 \%)$ \\
Negative attitude & $24(6.3 \%)$ \\
Neutral attitude & $2(0.5 \%)$ \\
\hline
\end{tabular}

Table 3 shows the attitude of mothers with children less than five years to information on hand washing. As the table indicates, most of the respondents, about 9 in 10 of them, had what could be described as positive attitude towards hand washing as they regarded hand washing as a healthy practice they will engage in because it is necessary for mothers. Only about $6 \%$ showed a not so encouraging 
attitude some of them said hand washing is important but time wasting or that they washed their hands when it is suitable.

With positive attitude established, the study investigated further the practice of hand washing among the mothers of children are who are less five years. Would they practice hand washing? The next table shows that about 8 in 10 mothers with children less than five years practiced hand washing (81.4\%).

Table 4. Hand wash practice

\begin{tabular}{|c|c|}
\hline Number of respondents & \\
Practice, $\mathrm{n} \%$ & $(\mathrm{n}=374)$ \\
Practicing & $301(81.4 \%)$ \\
Not practicing & $22(5.9 \%)$ \\
Not sure if practicing & $47(12.8 \%)$ \\
\hline
\end{tabular}

The respondents were asked to demonstrate what they did and for how long. Table 5 below established the pattern of hand washing practice.

Table 5. Pattern of hand washing practice

\begin{tabular}{|c|c|}
\hline Number of respondents & \\
Pattern, $\mathrm{n} \%$ & $(\mathrm{n}=374)$ \\
I do for between 1 and 9 seconds & $120(32.3 \%)$ \\
I do for between 10 and 19 seconds & $113(30.5 \%)$ \\
I do for between 20 and 29 seconds & $74(19.9 \%)$ \\
I do for up to 30 seconds and more & $64(17.3 \%)$ \\
\hline
\end{tabular}

Although the respondents practiced hand washing, those who did it in a wrong way were more than those who did rightly. Table shows that only $17.3 \%$ of mothers were doing proper hand washing. This indicates while the practice of hand washing was high among mothers of children less than five years in Lagos, they really were not doing it the hygienic way because when they washed their hands, they were not doing so long enough to prevent diseases.

\section{Discussion of Findings}

This study has made some revelations and they are presented as follows:

1. Most of the mothers of children less than five years had been greatly exposed to information on hand washing and this awareness has led to high knowledge of it as a good way to combat diarrhea and other children life threatening diseases.

2. It has been discovered that the attitude of mothers of children less than five years is positive. Access to information by the mothers is important in terms of influencing behaviour. Both Health Belief Model and the diffusion of innovation theory have information dissemination and knowledge sharing as key behavioural determinants. Exposure to hand washing information has created high knowledge and this has led to positive attitude and reception.

3. Most of the mothers of children less than five years have been found to practice hand washing.
However, such practice, when investigated further, did not match the recommended ways of doing. Only a few of them engaged in proper hand washing. While available information ensured that mothers of children less than five years had awareness and knowledge, as well as positive attitude to engage in hand washing, the findings have shown that such awareness and knowledge were inadequate as what they did was in opposite of what information on hand washing taught them.

4. The outcomes of this study corroborate those from the study conducted by Pittet and Boyce (2001) and the study of Bello, Effa, Okokon and Oduwole (2013) on the factors that influence hand washing practice. The studies in question established that hand washing practice may be influenced by an interplay of knowledge, belief, attitude and socioeconomic factors. In a similar vein, this study has established a nexus between awareness, knowledge and attitude of mothers of children less than five years and their practice of hand washing.

\section{Conclusions}

Hand washing is clearly an international agenda domesticated in individual countries, including Nigeria, to influence hygienic behaviour among mothers of children less than five years. A number of studies have produced a volume of literature on the benefits of hand washing, not just to reduce mortality rate of children less than five years, but also to combat common diseases, especially those with a faeco-oral transmission pattern. From the findings of this study, it is been established that although awareness, knowledge, attitude and practice was high, except hands of mothers are washed properly in accordance with instructions from hand washing information, desired results will not be achieved. The conclusions that can be reached from the findings are that one, the information provided on hand washing was not adequate or its intent was not clear for mothers to understand it. Chances are also, that everything could be right the information provided on hand washing but some beliefs held by the mothers prevented them from heeding the recommendations, thereby creating an impossible scenario maintain a proper hand washing culture.

\section{Recommendations}

1. The outcome recorded by this study suggests that with room for improvement, the campaigns from international organisations are influencing the way mothers of children less than five years to become aware and knowledgeable about the need to practice regular hand washing. However, there is still about a quarter of mothers of children less than 
five years who either low or no awareness and knowledge, it is recommended that the sponsors of the campaign should intensify efforts and increase exposure slot in the mass media in order to get more caregivers know about the benefits of hand washing.

2. The study has revealed that the practice of hand washing among the mothers of children less than five years is impressive but not properly done. It therefore means there is room for improvement. Efforts should therefore be made through the international agencies with supports from local authorities in the country to make more mothers practice and engage in washing their hands properly and at all times in order to prevent diseases of different types to children under five years.

Beyond mass media campaigns, there is the need also for interpersonal and community campaigns as a means of ensuring that hand washing becomes a part of popular culture. Opinion leaders, socio-political leaders, and even celebrities can form part of the campaign to encourage people, especially mothers of children less than five years, to practice hand washing, not as a passing fad, but as a survival lifestyle.

\section{REFERENCES}

[1] Nte R A. Child Survival in Resource-Limited Settings: The Issues, Challenges and Way Forward, Inaugural Lecture Series, No. 91; 2012, Port Harcourt: University of Port Harcourt,

[2] Curtis V, Cairncross S. Effect of washing hands with soap on diarrhoea risk in the community: a systematic review. Lancet; 2003, 3: 275-81

[3] Dutton P, Peschiera R F, Nguyen N K. The Power of Primary Schools to change and Sustain handwashing with Soap among children: the Cases of Vietnam and Peru, Lima, Peru: World Bank's Water and Sanitation Program; 2011

[4] Pengpid, S. and Peltzer, K. Hygiene behaviour and associated factors among in-school adolescents in nine African countries. Int J Behav Med. 2011; 18 (2): 150-9.

[5] Centre for Disease Control and Prevention. OPRP General Information on Hand Hygiene. [Internet] 2009 [Cited 2013 Dec 3] Available from http://www.cdc.gov/nc $\mathrm{eh} / \mathrm{vsp} /$ cruiselines/hand_hygiene_general.htm.

[6] Lancet. Executive summary: The Lancet's Series on Maternal and Child Undernutrition, [Internet] 2008 [Cited 2013 Nov. 12] Available from http://www.imagine.in/Sem 6-ExeSum.pdf

[7] Saha K K, Frongillo E A, Alam D S, Arifeen S E, Persson L A, Rasmussen, K M. Household food security is associated with growth of infants and young children in rural Bangladesh. Pub Health Nut, 2009; 12 (9); pp. 556-1562
[8] Vivas A G, Bizu A, Nigusu K, Abera BY, Williams M A. Knowledge, Attitudes, and Practices (KAP) of Hygiene among School Children in Angolela, Ethiopia. J Prev Med. Hygiene, 2010; 51; p. 73-79

[9] World Health Organisation. World health statistics 2015. Geneva, Switzerland; 2015

[10] Udo J J, Anah M U, Ochigbo S O, Etuk IS, Ekanem A D. Neonatal morbidity and mortality in Calabar, Nigeria: a hospital-based study. Nigeria Journal of Clinical Practice, 2008; 11(3); pp. 285-289

[11] Ogunsola F, Balogun M, Aigbefo S, Oduyebo O, Oladele R, Olufemi J, Ajieroh V. Perception and practice of hand washing in Kuramo Community, Lagos, Nigeria. Int. J Inf Cont. 2013, 9 (1)

[12] Black R E, Morris S S, Bryce J. Where and why are 10 million children dying every year? Lancet, 2003, 361: pp. 2226-34.

[13] Bowen A, Ma, H, Ou J, Billhimer W, Long T, Mintz E, Hoekstra RM, Luby S. A Cluster-randomized Controlled Trial Evaluating the Effect of a Hand washing-Promotion Program in Chinese Primary Schools. Am. J Trop Med. Hygiene, 2007, 76 (6); pp. 1166-73

[14] United Nations Children's Fund. Soap, Toilets, and Taps. A Foundation for Healthy Children. [Internet] 2009 [Cited 2013 Dec. 22] Available from www.unicef.org/wash/files/ FINAL

[15] United Nations Children's Fund. Some 35 million more children under five at risk if child mortality goal not met. [Internet] 2013 [Cited 2014 Feb. 15] Available from http://www.unicef.org/media/media_70371.html

[16] National Population Commission (NPC) [Nigeria] and ICF International. Nigeria Demographic and Health Survey 2013. Abuja, Nigeria, and Rockville, Maryland, USA: NPC and ICF International; 2014.

[17] National Population Commission (NPC) [Nigeria] and ICF Macro. Nigeria Demographic and Health Survey 2008. Abuja, Nigeria: National Population Commission and ICF Macro; 2008.

[18] World Health Organization (WHO) 2010 World health statistics 2010. Geneva, Switzerland: WHO. Retrieved online from http://www.who.int/whosis/whostat/eN_WHS 10_Full.pdf, on 18/12/2013

[19] Jamieson D, Breman JG, Measham A R, Alleyne G, Claeson M, Evans D B, Jhaet P et al [editors]. Disease Control Priorities in Developing Countries. Oxford: Oxford University Press; 2006

[20] Luby S P, Halder A K, Tronchet C, Akhter S, Bhuiya A, Johnston RB. Household characteristics associated with handwashing with soap in rural Bangladesh .Am J Trop Med Hyg, 2009, 81; pp. $882-887$

[21] Liu L, Johnson H L, Cousens S, Perin J, Scott S, Lawn JE, Rudan I, et al. (2012). Global, regional, and national causes of child mortality: an updated systematic analysis for 2010 with time trends since 2000. Lancet. 2012 Jun 9; 379 (9832):2151-61. doi: 10.1016/S0140-6736(12)60560-1

[22] Ensink, J. Health impact of handwashing with soap. WELL Factsheets, 2004 
[23] Luby S P, Agboatwalla M, Feikin D R et al. Effect of handwashing on child health: a randomised controlled trial. Lancet. 2005; 366: 225-233.

[24] Rabie, T. and V. Curtis. Handwashing and risk of respiratory infections: a quantitative systematic review. Trop Med Int Health, 2006, 11(3): p. 258-267.

[25] Centre for Disease Control and Prevention (CDC). 2014 Ebola Outbreak in West Africa - Case Counts [Internet] 2015 [Cited 2015 Jan. 12] Available from http://www.cdc.gov/vhf/ebola/outbreaks/2014-west-africa/ case-counts.html

[26] World Health Organisation (WHO). Ebola Situation Report. [Internet] 2015 [Cited 2015 Jan. 12] Available from http://www.who.int/csr/disease/ebola/situation-reports/en/

[27] Centre for Disease Control and Prevention (CDC) Hand Hygiene in West African General (Non-ETU) Healthcare Settings. [Internet] 2014 [Cited 2015 Jan. 12] Available from http://www.cdc.gov/vhf/ebola/hcp/hand-hygiene.html

[28] Global Private-Public Partnership for Handwashing. Handwashing and Ebola: The facts. [Internet] 2014 [Cited 2015 Jan. 17] Available from http://globalhandwashing.org /resources/general/handwashing-ebola-factsheet

[29] O'Brien K L, Wolfson L J, Watt J P, et al. Burden of Disease Caused by Streptococcus Pneumoniae in Children Younger than 5 Years: Global Estimates. Lancet. 2009; 374(9693); pp. 893-902.

[30] Watt J P, Wolfson L J, O'Brien K L, Henkle E, DeloriaKnoll M, McCall N, et al. Burden of disease caused by Haemophilus influenzae type $\mathrm{b}$ in children younger than 5 years: global estimates. Lancet. 2009; 374; pp. 903-11. doi: 10.1016/S0140-6736(09)61203-4

[31] Isibor H. Only 3\% of Nigerians wash regularly with soap Unilever. [Internet] 2013 [Cited 2013 Feb 3] Available from

https://www.vanguardngr.com/2013/10/3-nigerians-wash-r egularly-soap-unilever/

[32] Luby S P, Halder A K, Huda T, Unicomb L, Johnston R B. The Effect of Handwashing at Recommended Times with Water Alone and With Soap on Child Diarrhea in Rural Bangladesh: An Observational Study. PLoS Med, 2011, 8(6): e1001052.https://doi.org/10.1371/journal.pmed.1001 052

[33] World Bank (WSP). Water and Saniation Program (Learning Note), Behavioral Determinants of Handwashing with Soap among Mothers and Caretakers: Emergent Learning from Senegal and Peru. [Internet] 2012 [Cited 2013 Feb 3] Available from: http://www.wsp.org/wsp/sites /wsp.org/files/publications/WSP-Behavioral-DeterminantsHandwashing-With-Soap.pdf

[34] United Nations Children's Fund. Water, Sanitation and Hygiene: 2012 Annual Report. [Internet] 2013 [Cited 2016 Sept. 13] Available from https://www.unicef.org/wash/files/2012_WASH_Annual Report_14August2013_eversion_(1).pdf

[35] Pittet D, Boyce JM. Hand hygiene and patient care: pursuing the Semmelweis legacy. The Lancet Inf. Dis., 2001; 1 (0): pp. 9 - 20
[36] Bello S, Effa E E, Okokon E O, Oduwole O A. Handwashing practice among healthcare providers in a teaching hospital in southern Nigeria. Int J Inf Cont, 2013, 9 (4).

[37] Lu, S. and Wu, A. Clean-Hands: Promotion of Hand Hygiene. [Internet] n.d [Cited 2014 Mar. 14] Available from

http://www.hsi.gatech.edu/onsitecenter/images/d/d5/Finalr eportCleanHands.pdf

[38] Orsola-Vidal A, Yusuf A. Scaling Up Handwashing Behaviour: Findings from the Impact Evaluation Baseline Survey in Senegal. Washington: World Bank; 2011

[39] Mahamud A S, Ahmed J A, Nyoka R, Auko E, Kahi V, Ndirangu J, et al. Epidemic cholera in Kakuma Refugee Camp, Kenya, 2009: The importance of sanitation and soap. J Infect Dev Ctries. 2012; 6(3); pp. 234-41.

[40] World Bank (WSP). Are your hands clean enough? Study Findings on Handwashing Behaviour in Kenya. [Internet] 2012 [Cited 2013 Mar 12] Available from http://www.wsp.org/wsp/sites/wsp.org/files/Handwashing Behavior_Book.Final_.pdf.

[41] Steadman-Group. Formative and baseline survey on handwashing with soap: final report. Nairobi, Kenya: Steadman-Group. 2007

[42] Aunger, R., Schmidt, W., Ranpura, A., Coombes, Y., Maina, P. M., Matiko, C. N., and Curtis, V. 2009 Three kinds of psychological determinants for hand-washing behaviour in Kenya, Soc. Sci. Med, xxx, 2009; pp. 1-9

[43] Steiner-Asiedu M, Van-Ess SE, Papoe M, Setorglo J, Asiedu D K, Anderson A K. Hand Washing Practices among School Children in Ghana. Current Research Journal of Social Sciences, 2011, 3(4): pp. 293-300

[44] Affleck, W. and G. Pelto, Caregivers' responses to an intervention to improve young child feeding behaviors in rural Bangladesh: A mixed method study of the facilitators and barriers to change. Soc Sci Med, 2012, 75(4): pp. 651-8.

[45] Champion V L, Skinner C. The health belief model. In: Glanz, K, Rimer BK, Viswanath KV. (Editors). Health Behavior and Health Education: Theory, Research and Practice. (4th ed) San Francisco: Jossey-Bass; 2008 (pp. 46-65).

[46] Ahadzadeh A S, Pahlevan S S, Ong F S, Khong KW. Integrating Health Belief Model and Technology Acceptance Model: An Investigation of Health-Related Internet Use. J. Med Int Research, 2015. 17 (2): e45

[47] Rosenstock I M, Strecher V J, Becker M J. The health belief model and HIV risk behaviour change. In DiClemente RJ, Peterson J L (editors), Preventing AIDS: theories and methods of behavioural interventions. New York: Plenum Press; 1994. (pp. 5-24)

[48] Yun E K, Park H A. Consumers' disease information-seeking behaviour on the Internet in Korea. J. Cl Nrsg, 2010, 19 (19-20): pp. 2860-2868.

[49] Rosen L, Zucker D, Brody D, Engelhard D, Manor O. The effect of a handwashing intervention on preschool educator beliefs, attitudes, knowledge and self-efficacy. Hlth Ed. Research, 2009, 24 (4): pp. 686-698. 
[50] Abouzelof R H. Diffusion of innovations: Describing the perceptions of the stages in the innovation-decision process for handwashing and alcohol hand rubs. M.S.N: University of Utah College of Nursing; 1999

[51] McManus A. Health promotion innovation in primary health care. AMJ 2013, 6, 1, 15-18. http//dx.doi.org/10.406 6/AMJ.2013.1578

[52] Rogers, E M. Diffusion of innovations (revised ed). New York: Free Press; 2003.

[53] Orr, G. Review: Diffusion of Innovations by Everett Rogers (1995). [Internet] 2003 [Cited 2014 Mar 12] Available from http://www.stanford.edu/class/symbsys205/Diffusion \%20o $\mathrm{f} \%$ 20Innovations.htm

[54] Eshuachi, R. Promoting Handwashing with Soap Behaviour in Kenyan Schools: Learning From Puppetry Trials among Primary School Children in Kenya. [Unpublished Ph.D. Thesis]. Queensland: Queensland University of Technology; 2013.
[55] Water Supply and Sanitation Collaborative Council. Water, Sanitation and Hygiene for all - the WASH Campaign. [Internet] n.d. [Cited 2014 Mar 12] Available from www.un.org/spanish/conferences/.../wash_campaign_note _020125.doc

[56] Bertrand J. Diffusion of Innovations and HIV/AIDS. J. Hlth Comm., 2004, 9: pp. 113-121

[57] Curtis V, Aunger R, Rabie T. Evidence that disgust evolved to protect from risk of disease. Proceedings of the Royal Society B., 2004, 271(Suppl. 4), S131-133.

[58] Ryerson, W. The Effectiveness of Entertainment Mass Media in Changing Behavior. [Internet] 2008 [Cited 2015 May 20] Available from http://www.populationmedia.org/ wp-content/uploads/2008/02/effectiveness-of-entertainmen t-education-112706.pdf

[59] Dearing J W. Applying Diffusion of Innovation Theory to Intervention Development. Res. Soc. Work Pract. 2009; 19(5): pp. 503-518. doi:10.1177/1049731509335569. 